\title{
LAS MEDIDAS GUBERNATIVAS EN LA CRISIS SANITARIA DE 1803-1805
}

\author{
Sarah Caro Bragado \\ Hospital Guadarrama \\ Email: cefcarolo@yahoo.com \\ ORCID iD:https://orcid.org/0000-0002-0380-865X \\ Ceferino Caro López \\ I.E.S. "Beatriz Galindo" de Madrid \\ Email: cefcarolo@yahoo.com \\ ORCID iD:https://orcid.org/0000-0003-3412-6333
}

Recibido: 10 octubre 2018; Aceptado: 4 noviembre 2020

Cómo citar este artículo/Citation: Caro Bragado, Sarah; Caro López, Ceferino (2021) "Las medidas gubernativas en la crisis sanitaria de 1803-1805", Asclepio, 73(1): p340. https://doi.org/10.3989/asclepio.2021.06

RESUMEN: La crisis de producción de 1803-1805 fue acompañada de muchos casos de fiebres palúdicas agravadas por la pobreza del mundo rural. Este trabajo intenta una aproximación a las medidas de alivio de pobres y enfermos mediante el análisis de los expedientes de petición de socorro presentados al Consejo de Castilla. El gobierno actuó sobre una línea doble; por un lado la ayuda a los enfermos con provisiones de quina y el recurso a la sopa económica, y por otro la promoción de trabajos públicos para dar trabajo a los jornaleros desocupados. Los poderes locales descubren las pésimas condiciones higiénicas de sus pueblos y se emprenden obras de construcción de fuentes y drenaje de aguas estancadas. El resultado global fue muy limitado debido a la escasez de fondos disponibles porque todo el peso de la financiación recaía sobre los ayuntamientos. Al llevar a cabo las obras precisas los pueblos se empobrecían ulteriormente dado que debían recurrir a la venta de comunales o a empréstitos que más tarde habrían de reembolsar.

PALABRAS CLAVE: paludismo; sopa económica; sanidad pública.

\section{GOVERNAMENTAL MEASURES IN THE HEALTH CRISIS OF 1803-1805}

ABSTRACT: The production crisis of 1803-1805 ushered in many cases of malaria fevers, exacerbated by the poverty of the rural world. This paper aims at approaching the measures of relief for the poor and the sick by analysing the requests for help files addressed to the Consejo de Castilla.The government acted following a twofold line: on the one hand to relieve the sick by supplying quinine and resorting to the sopa económica, and on the other by promoting public works in order to employ the unemployed day labourers. Local authorities suddenly realized their villages' dreadful hygienic situations and started a campaign of building fountains and draining stagnant waters. The overall result was very limited owing to the scarcity of funds available, because the whole economic burden was to lay on the village councils. Carrying out these works the villages subsequently became poorer because they had to resort to selling community property or to loans that would have been repaid later.

KEY WORDS: Malaria Fever; Economic Soup; Public Healthcare.

Copyright: (C) 2021 CSIC. Este es un artículo de acceso abierto distribuido bajo los términos de la licencia de uso y distribución Creative Commons Reconocimiento 4.0 Internacional (CC BY 4.0) 


\section{INTRODUCCIÓN}

Entre 1803 y 1805 fue necesario hacer frente a una emergencia sanitaria de epidemias de tercianas ${ }^{1}$ en un mundo, rural o urbano, que se hallaba a la merced de la enfermedad y aún más indefenso si un período de malas cosechas precipitaba la malnutrición o el hambre como ocurrió con la crisis de producción en esos años. Unos pocos ejemplos valdrán para ilustrar la situación desesperada de muchos pueblos: en Los Yébenes sufrían la "terrible epidemia de tercianas y la escasez y enorme carestía de los granos". "Se nos mueren los pobres por las calles", decían en Robledo de Chavela. Cedillo informaba de que "morían bastantes vecinos [...]y esto por la mucha miseria". En Lorca

[...] la extrema miseria que han padecido estos habitantes, [...] el uso que han hecho de alimentos de mala calidad y difícil digestión han producido una epidemia de tercianas [...] que a los principios eran benignas pero ya se van malignando en términos que mueren en bastante número $[\ldots]^{2}$.

El gobierno estaba ya ocupado en la lucha contra la fiebre amarilla, intentando sistematizar las actuaciones sanitarias, como demuestra la Real Orden2 de septiembre de 1803 mandando compilar un nuevo Código de Sanidad, previa a cualquier otra disposición. Se avisaba al Consejo de Castilla de que se le remitían los tres tomos que contienen los Reglamentos, Edictos, e Instrucciones de Sanidad expedidas en diferentes tiempos desde el año 1720 en que con motivo de la peste de Marsella se tomó este importante ramo de policía con la consideración que pide su trascendencia, creándose la Junta Suprema de Sanidad y estableciéndose los resguardos particulares en los Puertos del reino ha- bilitados para el Comercio nacional y extranjero [...] Ha resuelto S.M. que se proceda a la formación del nuevo Código de Sanidad con la brevedad y preferencia que exige la importancia de este objeto [...] y devuelvo adjuntos dichos tres tomos a fin que la Junta Suprema de Sanidad no carezca de esta interesante compilación.

Para las epidemias palúdicas aparecieron el Dictamen 23de noviembre de 1803, seguido de la Real Resolución 22 de diciembre del mismo año referida a las dos Castillas y en 1804 otro expediente sobre pobres enfermos. Se legisló también para activar las Juntas de Beneficencia, con Reales Órdenes 18 de septiembre de 1803 a las Sociedades Económicas, y 15 de enero y 26 de diciembre de 1804. En 1805 el Consejo se ocupó de la sanidad y la higiene públicas; además la Carta Circular 17 de noviembre de 1804 fomentaba las obras públicas para ocupar a los jornaleros ${ }^{3}$. A estas medidas hay que añadir las dos importantes Reales Órdenes8 de septiembre y 7 de octubre de 1803 con las que se planteaba una acción general de auxilio a los afectados, pobres, enfermos y desempleados, y son precisamente esas medidas las que dieron pie a las peticiones de socorro que son la base documental de este estudio ${ }^{4}$. Salta a la vista la gravedad de la situación pues solamente en 1803 se concentra el $70 \%$ de todas las representaciones llevadas al Consejo de Castilla entre 1780 y 1808 , y en 1804 se vieron las mismas peticiones que entre 1781 y 1802 . Dirigirse al gobierno para obtener un subsidio o favor especial era práctica corriente durante toda la Edad Moderna, pero lo que explica el crecido número de peticiones en 1803-1804 es por un lado la dureza de la crisis y por otro la política asistencial del Consejo.

CUADRO 1.- Relación de pueblos afectados por la crisis sanitaria de 1803-1805, por regiones actuales.

\begin{tabular}{|l|l|l|l|l|}
\hline Regiones & casos & & Regiones & casos \\
\hline Andalucía & 41 & & Extremadura & 20 \\
\cline { 1 - 1 } Aragón & 2 & Galicia & 2 \\
\cline { 1 - 1 } Asturias & Murcia & 10 \\
\hline Castilla La Nueva & 64 & P. Vasco & 1 \\
\cline { 1 - 1 } Castilla La Vieja & 66 & Total documentado & 209 \\
\hline
\end{tabular}

CUADRO 2.- Peticiones de socorro durante la crisis en relación con el período 1780-1808.

\begin{tabular}{|l|l|l|l|l|l|l|l|l|l|l|l|l|}
\hline AÑO & 1781785 & $1786-1790$ & $1791-1795$ & 17961800 & 1801 & 1802 & 1803 & 1804 & 1805 & 1806 & 1807 & 1808 \\
\hline CASOS & 4 & 6 & - & 4 & 1 & 9 & 142 & 24 & 9 & 1 & 1 & 3 \\
\hline
\end{tabular}




\section{EL ENFOQUE DEL PROBLEMA}

Para valorar exactamente el significado de la política del Consejo de Castilla habrá que recordar que la medicina contemporánea barajaba varias explicaciones sobre la naturaleza del mal y la propagación de las epidemias. La "teoría miasmática del contagio "de raigambre hipocrática centraba su interés en las condiciones de la atmósfera y la acción de los miasmas, “imperceptibles seres volátiles producto de la descomposición de la materia orgánica y que gustaban para su desarrollo de los lugares cálidos, húmedos y sombríos" (Bonastra, 2000). Para los autores de la época el origen de la enfermedad era evidente en las aguas estancadas; Masdevall, Alsinet, Salazar, insisten en el peligro de las aguas "variamente alteradas y corrompidas", de "todo paraje donde hay poca ventilación y quedan aguas encharcadas". Sin embargo los médicos reconocían también razones sociales que agravaban la enfermedad como

la muchísima miseria que se ha padecido en dichos Países de algunos años a esta parte, por las malísimas cosechas que nos ha ocasionado la sequedad y falta de Iluvia en este Principado,

según apuntaba Masdevall ${ }^{5}$.

Es interesante notar que parece que el gobierno sin embargo prefería minimizar en parte las consideraciones sociales, con un "si bien han influido no poco [...] con independencia de aquella causa..." y apuntaba a otro factor, el determinismo geográfico/climático y la insalubridad de muchos pueblos "que necesariamente debían producir las tercianas...". Prestaba más atención a las causas ambientales físicas de la enfermedad que a los aspectos sociales que la complicaban:

Por estas exposiciones de los médicos comisionados se viene en conocimiento de la situación topográfica de los pueblos que visitaron en cuanto puede influir en su salubridad y se ve que si bien ha influido no poco para las enfermedades la constitución infeliz de sus habitantes por las malas cosechas los últimos años, hay con independencia de aquella causa otras, que necesariamente debían producir las tercianas, hidropesías y demás dolencias de igual clase, [...] las aguas estancadas de que está inundada la provincia, cuando por la acción del calor se descomponen las mismas aguas y los cuerpos contenidos en ellas, habiendo sido el número y violencia de los males en razón directa de la cantidad de aguas inmediatas a las poblaciones, y del influjo de las causas, que favorecen dicha descomposición ${ }^{6}$.

Era la constatación casi fatalista de una situación inevitable. La lógica solución debería pasar entonces por "que se d[iera] salida a todas las aguas estancadas, limpiando el cauce de los ríos y arroyos [...] reparando las márgenes arruinadas por las inundaciones" y en febrero de 1804 el rey encargó al Consejo que tomara las medidas "a fin de desecar o dar vertiente según conviniese a dichas lagunas y charcos y a las aguas corrompidas" lanzando así una política de intervención en la salubridad pública.

Con el reconocimiento de la miseria de la población la tarea del gobierno se presentaba bajo tres aspectos distintos e imbricados: primero, el puramente médico de combatir el paludismo, para lo que el único recurso era la quina. El segundo consistía en proporcionar a los enfermos pobres la alimentación necesaria para resistir a la enfermedad, lo que se llevó a cabo con la sopa económica; se puede entender como intervención pasiva. El tercer frente abierto era la necesidad de actuar un plan de saneamiento y mejora de las condiciones higiénicas de ciudades, villas y lugares. Para esta tarea se tuvo en consideración la pobreza generalizada del momento y la iniciativa sirvió también para proporcionar trabajo a los jornaleros desocupados a causa de la crisis.

El problema de la pobreza y la enfermedad. Además de los problemas crónicos de todos los estados en la Edad Preindustrial para proveer de granos a la población en tiempos de crisis, se trataba ahora de proporcionar una comida a pobres y/o enfermos. Hay precedentes de este recurso, con carácter limitado en el tiempo o circunscritos a un lugar concreto, antes de su promoción generalizada durante la crisis, por ejemplo en 1788 en la provincia de Valladolid. Entonces se repartió una suerte de sopa boba para socorrer a "los pobrecitos enfermos necesitados por falta de alimentos y medicinas, sin lo que no puede hacer su efecto la quina", pero la denominada oficialmente sopa económica aparece durante la crisis mediante Reales Órdenes 18 de septiembre y 26 de diciembre de 1803 declarando que su reparto sería competencia de los ayuntamientos. Se la conocía en España desde 1800, cuando se presentó en la Sociedad Matritense la obra del conde Rumford. La sopa original consistía en cebada, guisantes y patatas cocidos, revueltos para "reduire les ingrédients à une seule substance", a los que se añadía vinagre y sal y se servía con pan "très sec et dur" en ración de una libra de Baviera (561 g.). Según Rumford "cette portion de soupe tient lieu d'un bon repas à une personne forte et vigoureuse" ${ }^{\prime 7}$, pero los madrileños no encontraban tal alimento de su agrado, como revela Paula Demerson. En Madrid las autoridades se preocupaban por "los "remilgos» del público no acostumbrado a ese tipo de manjares", igual que 
ocurriría en otros lugares más tarde, como se verá. Las pruebas habían producido una suerte de puré insípido "aunque sano" que en opinión de los comisionados no sería apetitoso para el paladar de los españoles; modificando la receta pretendían también repartir el pan en rebanadas y no dentro de la sopa. En octubre de 1803 iniciaron los trabajos preparatorios para el reparto en la Corte; en 2 de octubre otra Real Orden encomendaba a las Sociedades de Amigos del País en todo el reino que hicieran lo mismo. Es interesante notar que la distribución en Madrid acabó a finales de abril no sólo por agotamiento de los fondos, sino porque se pensaba que la sopa difícilmente se aceptaría en tiempo de verano ${ }^{8}$.

En 1803-1804 las actuaciones locales no se hicieron esperar, señal de la gravedad de la situación. En Madrigal repartían una sopa que consistía en una libra (460 g.) de cocido y media de pan "a las personas grandes y algo menos a los muchachos [...] por lista y gratuitamente porque todos los que la reciben son miserables". En Berlanga la "comida económica o cocido" de ración de una libra se componía de "arroz, alubias y nabos con el agregado de un cuarterón de pan". En Salamanca era una "buena ración de sopa de patatas, tocino, alubias o arroz, y el pan correspondiente". En Riaza no podían seguir la receta porque el territorio no producía la materia prima, "almortas, guisantes y demás especies precisas", con lo que se puede apreciar que la receta se adecuaba a las realidades y productos locales. La sopa de Salvatierra en 1805 estaba hecha de "alubia, arroz, pimiento, sal y aceite" con una ración de pan "como de ocho a diez onzas" (230-290 gramos) "sin dejar por eso de suministrar algunas raciones de carne diariamente a los enfermos según su posibilidad" (de la Junta) ${ }^{9}$. El informe de Córdoba de 1805 sobre comidas económicas "para los pobres, a quienes es casi imposible alcanzar el pan por su excesivo coste", concluía que "esta Sopa e[ra] sabrosa, saludable y nutritiva", y había tenido éxito entre los necesitados, desmintiendo a "los que creían que en Córdoba sería impracticable su uso por la repugnancia de las gentes a unos compuestos desconocidos en el país por su natural abundancia de las producciones de primera necesidad, especialmente la del trigo". Claro que la receta cordobesa era muy distinta de la original. Una vez descartado el pan por carísimo, había habido que dar con otros alimentos "que no se desprecien, ya el maíz, las patatas y otras comidas, que no tienen contra sí más razón que el no haberlas comido hasta ahora". La Junta de Sanidad había hecho "una comida barata, sabrosa y nutritiva, para la que no se necesita[ba] pan" compuesta de dos partes y media de habas y harina de maíz por una de arroz, aceite, sal, pimiento picante, cebollas, ajos "y la cantidad de yerbabuena que es suficiente; y se le añade algún pimiento dulce, para darle buen color", adaptándola "a las circunstancias del país y al melindroso paladar de sus habitantes". El factor gastronómico jugaba su papel pero no se perdía de vista el principal aspecto, el económico, pues el informe también avisaba de que

podría hacerla más barata el poner en ella alguna cantidad de nabos, como lo hacían en la Castilla, rebajando otra tanta de habas; al maíz puede sustituirse la cebada, aunque no da tan buen gusto; en lugar de pimiento dulce puede usarse el achote ${ }^{10}$, y en vez de yerbabuena cogollitos de hinojo.

La receta se especificaba aún más en una nota que decía que era

más económico y mucho más oportuno el clavo redondo o pimienta de tabasco. Es género de nuestras Américas, más sano que las pimientas y clavo extranjero, y tan barato, que en Cádiz se despacha la libra a 4 reales. La comida económica adquiere con él un olor y sabor muy gratos, y es lástima que no se haga más uso de esta especia en nuestras cocinas ${ }^{11}$.

El precio calculado de cada ración era medio real "a lo que añadiendo el valor del combustible puede darse de comer a un pobre con su ración diaria [575 gramos] toda una semana por el corto precio de una peseta". Porque el factor económico era de crucial importancia.

El instrumento diseñado para implementar las tareas de auxilio a los enfermos pobres, aunque tenía otras funciones también, era la Junta de Beneficencia o Socorro establecida por Real Orden 15 de enero de 1804 , destinada en un principio a las dos Castillas. Antes, con la Real Resolución 22 de diciembre de 1803, el rey se había interesado por proporcionar "aquel prodigioso específico"-la quina ${ }^{12}$ - pero después, en 1804, habían llegado a conocimiento del rey las noticias de la situación de tantos pueblos

de las dos Castillas, infestados por la perniciosa epidemia de tercianas [...] y habiendo sabido por los informes de los Intendentes respectivos que las causas generales de este mal son el descuido en la policía, la miseria de los jornaleros y demás clases indigentes por la corta cosecha que ha precedido, y la falta de medicinas al propósito,

y una Real Orden dictaba que para asistir a los pobres enfermos se les ofrecieran los granos del Fondo pío beneficial y de Tercias "que tengan desembarazados la Dirección de Provisiones, a calidad de reintegro estos últimos" y también de los fondos de Propios y 
Pósitos exceptuando los ya comprometidos en el reintegro de los 300 millones. También podrían disponer de los fondos de "conmutaciones de obras pías" y hermandades, "manifestando desde luego a todos los Pueblos que, cualesquiera que sean sus fundaciones, nunca podrán invertirse en fines tan sagrados e interesantes al bien público, cuyos respetos hacen cesar cualquiera otra consideración que pudiera sugerir una piedad mal entendida". La Real Orden acentuaba la necesidad de fomentar la generosidad de los particulares y autorizaba la adopción de algunos

arbitrios temporales durante las presentes necesidades, con tal que convengan en ello los Pueblos que han de sufrirlos, y que se excluya del aumento del precio que se imponga sobre los consumos a los pobres enfermos que califiquen estas dos circunstancias con certificación de las Juntas de sus Pueblos respectivos, que han de entender en la distribución de dichos caudales.

Además se estipulaban facilidades en el pago de las rentas de los colonos para evitar que cayeran en la miseria total ${ }^{13}$. Es decir que las medidas para remediar las epidemias pasaron por ley de proporcionar sencillamente el medicamento específico a intentar asegurar el suministro de los alimentos básicos, principalmente el pan a quien pudiera pagarlo, o una comida de caridad a los pobres. La Real Orden se refería en sus principios a las dos Castillas, pero otros muchos lugares de la Península también apelaron a ella para encarar la crisis. Mientras la fiebre amarilla causaba estragos en el Sur y Levante, los expedientes tras la Circular 7 de octubre se originaban en las dos CastiIlas (68\% de las representaciones) frente al $14,3 \%$ de Andalucía, y las peticiones de socorro por epidemias de malaria procedían en un $68,6 \%$ de ambas Castillas y sólo en un $11 \%$ de las zonas de fiebres amarillas, lo que se explica porque buena parte de esas zonas no estaban sujetas al control del Consejo. Las provincias más afectadas por el paludismo fueron Toledo y Guadalajara (9,8\% de las representaciones cada una) y Extremadura (11,8\%). En cambio, en las peticiones generales de ayuda, las más presentes son Toledo $(11,8 \%)$,Ciudad Real $(8,4 \%)$ y Extremadura (7,6\%).

\section{LAS LIMITACIONES ECONÓMICAS DE LOS PODE- RES PÚBLICOS}

El problema que se planteaba era cómo allegar los fondos necesarios para acometer esa atención, problema agravado por la lentitud burocrática, la realidad desastrosa de los fondos concejiles, la dependencia de la generosidad de los pudientes -limosnas- a lo que hay que añadir, como se verá más abajo, una actitud rayana en la prevención contra los necesitados. Analizando la recepción de las representaciones de los pueblos se nota que desde el principio el estado general de indigencia de tantos ayuntamientos grandes o pequeños no fue tomado debidamente en cuenta, ni las dificultades a que se enfrentaban cuando trataban de recurrir a caudales de propios, pósitos, fondos píos, rentas... pues a menudo las Contadurías Generales impedían esas acciones por motivos técnicos o legales, en detrimento de las necesidades inmediatas de unos enfermos "miserables que por serlo no dejan de ser hombres" como decía Hinojosa del Marquesado ${ }^{14}$. Por tratarse de una urgencia el Consejo autorizaba que se sacaran las cantidades precisas de los fondos de propios y arbitrios o si no las hubiere del pósito, "con calidad de reintegro", es decir, que no serían actuaciones a fondo perdido sino préstamos o adelantos en favor de la futura Junta de Beneficencia; lo que no se aclaraba era de qué manera este organismo se desempeñaría una vez pasada la emergencia.

Los arbitrios para encontrar fondos se convirtieron en la preocupación principal de muchos concejos. En Cuenca, por ejemplo, en 1804 la Junta de Caridad había promovido suscripciones públicas y con ellas y los sobrantes de propios de los pueblos y de las obras pías y hermandades había conseguido 81.344 reales para los enfermos pobres de la ciudad, que eran 191, para "media libra (200 g.) de carnero diaria, dos onzas(50 g.) de garbanzos, la medicina necesaria y una libra de pan además a los convalecientes" -nótese que ni era ni se llamaba sopa económica-. Pero faltaba dinero para continuar con los auxilios y además estaba el problema de las leyes que podían causar fricciones entre los varios organismos asistenciales: la Real Orden 18 de septiembre se dirigía a la Sociedades Económicas, la Real Cédula 26 de diciembre interesaba a las Juntas de Beneficencia, y la distribución de la sopa económica debería ser competencia de los ayuntamientos.

Además del recurso a fondos de propios o de los pósitos, otro blanco eran las obras pías que ya habían sido objeto de desamortización a finales del Setecientos. Para recaudar fondos también valían otros recursos que en el pasado se habían empleado con distinto objeto. En Toledo en 1804 por ejemplo valdrían los arbitrios para hacer frente a la repartición de los 300 millones que consistían en "el arrendamiento de las tierras entre árboles del paseo de la Vega" ${ }^{15}$ y el fiscal del Consejo no planteaba objeciones. 


\section{EL PROBLEMA DE LA HIGIENE PÚBLICA}

Los poderes locales tomaron la Carta Circular 7 de octubre de 1803 de fomento de empleo a los jornaleros en paro para emprender obras de saneamiento y mejora en la higiene pública. Por ello no tardaron en proponer actuaciones prácticas que consistían muy a menudo en "encañar" las fuentes públicas y "hacer buena madre" de los arroyos que causaban "la putrefacción" de los pueblos. Probablemente se puedan considerar estas medidas en el reflejo de la nosopolítica dieciochesca, para señalar la intervención estatal en la reglamentación de la práctica de la medicina y también, sobre todo, la toma de conciencia por parte de la sociedad de que salud y enfermedad eran problemas sociopolíticos que había que resolver de manera global. La nosopolítica del siglo XVIII consideraba que la salud era uno de los objetivos básicos de la acción política; de ahí las medidas de suministro de agua potable, ventilación urbana, racionalización urbanística ${ }^{16}$. En relación con este punto Sáez y Marset indican que en Murcia en los primeros 60 años del siglo Dieciocho se habría manifestado ya una "consolidación de la sanidad municipal" siguiendo los parámetros de la teoría nosopolítica sobre reglamentación de la medicina, "Pero sobre todo se manifiesta poniendo en marcha reformas urbanísticas (alcantarillado, abastecimiento de aguas, empedrado de las calles para facilitar su limpieza)". Sáez y Marset reconducen la política de salud pública a los diseños del Estado Moderno (1990, pp. II, IV), pero es de notar que en la contingencia de 18031805 la sugerencia genérica pudo venir de arriba, pero las propuestas de actuación concretas se originaron de los poderes locales, muchas veces en pugna con la postura del gobierno.

La atención de los concejos debía centrarse en evitar la continuación y propagación de las enfermedades padecidas en los años anteriores y en el momento, así que la evidente preocupación por la higiene pública que aparece en las representaciones va en paralelo con el interés del Gobierno por eliminar las amenazas a la salud, de manera que la primera alimenta al segundo y éste a su vez refuerza a la primera. Lo que indica el verdadero estado de la cuestión es que en el momento de lanzar una campaña de salubridad pública el Consejo de Castilla descubría que no había normativas específicas sobre el asunto y buscaba indicaciones provisionales hasta que se promulgaran leyes generales para todo el reino. Pero por las fechas de los expedientes se puede comprobar que la necesidad de combatir las condiciones antihigiénicas potencialmente peligrosas se notan primero en los pueblos, desde 1803 o incluso antes en algunos casos, y solamente en 1805 el Consejo tomaba el asunto en consideración, para reconocer que

no se halla $[b a] n$ en la Escribanía de Gobierno antecedentes algunos relativos a la policía de los pueblos en general, y por lo que pueda conducir, se ha puesto en este expediente un ejemplar de la Instrucción de Corregidores cuyo capítulo 58 trata de este punto.

En realidad ese apartado sólo muy genéricamente se podría tomar como base para la prevención sanitaria: decía que los intendentes deberían hacer guardar "limpieza, ornato, igualdad y empedrado de las calles" como si estuvieran más preocupados en los aspectos estéticos que en los sanitarios; había que derribar los edificios en mal estado y hacer calles "más anchas y derechas"; siguiendo esas indicaciones eso es lo que había hecho Alsinet en Aranjuez. Los fiscales del Consejo opinaban que convenía informar a los corregidores "según lo exigieren las circunstancias de los pueblos removiendo todo lo que pueda ofender a la salubridad del vecindario" pero dejándolo en segundo plano; el gobierno se limitaba en realidad a recomendaciones de buena voluntad sobre el cuidado del "aseo y limpieza", porque su capacidad de actuación estaba muy limitada por la falta crónica de fondos, pero también paradójicamente por la misma intervención del Consejo, a causa de la minuciosa reglamentación de su Carta Circular. Por ello, puede ser por falta de confianza, la Junta de de Azauchal decidía primero "que se comp[usier]a la cañería del agua potable" y después solicitaba al Consejo la bendición de los gastos, cubiertos con caudales del Fondo de Utensilios; aunque en 1806 el expediente seguía abierto, al menos la obra se había realizado ${ }^{17}$. Ese modo de proceder del pueblo evitó la lentitud de la burocracia y consiguió lo que muchos otros concejos pidieron sin alcanzar.

Al analizar las representaciones de los pueblos parecería como si, a raíz de las indicaciones del gobierno, el horror y la dureza de la enfermedad hubieran abierto los ojos de los vecinos sobre las condiciones higiénicas en que vivían: oyendo las recomendaciones de los médicos, pronto por todas partes se imponía la necesidad de velar por la salud pública, comprometida hasta puntos increíbles incluso para los contemporáneos. En Valladolid se emprendió una limpieza general de la ciudad que desde la fundación de ella no se había ejecutado igual, y que era mayor que aun la de las calles, que por algunas no era posible transitar por el horror que causaba su fetidez, la porquería que encerraban las casas en sus desvanes, quede algunas se han sacado 16 y 17 carros de ella, con el abuso de 
criarse hasta los cerdos en los mismos desvanes por no bajar a la calle lo que diariamente recogían dentro de las mismas.

En Escalona la costumbre de arrojar basuras indiscriminadamente "era inveterada" como de repente descubría el alcalde, viendo que las calles de su pueblo

s[ervía]n de muladares y estercoleros en tal grado que en algunas se halla interceptado el paso de forma que está expuesta dicha villa por falta de policía a contraer epidémicas enfermedades

(subrayado en el original) aunque el Consejo no contestaba a su representación. Es causa de asombro que en Medina Sidonia hasta 1802 nadie hubiera reparado en la suciedad

que producen distintos animales, como palomas, gallinas y aun cerdos que se alimentan dentro de las mismas casas; las calles siempre contienen porciones inmundas, fétidas y corrompidas que fatigando el olfato dañarán a la pública salud ${ }^{18}$.

La conciencia de los peligros de la enfermedad y el conocimiento de sus causas llevaba a criticar el desarreglo en la construcción de retretes, servidumbres o lugares comunes, "permitiendo tenerlas llenas exhalando sus malos olores y arrojando a las calles lo que debían contener aquellas casas donde se carece de estos depósitos formando varias aguas corrompidas" ${ }^{\prime 19}$.

El caso extremo en la intervención nosopolítica es el de José Alsinet, médico en Aranjuez, quien siguiendo al pie de la letra la necesidad de purificar el aire de la población había emprendido la demolición de las

casas, que formaban las desiguales y estrechas calles de la antigua población construyendo otras de más hermosa y elevada fábrica en distintas manzanas, tiradas en línea ${ }^{20}$.

La purificación del aire se había conseguido además con "el continuo y abundante humo que sale de tantas chimeneas de las nuevas habitaciones" y también es cierto que las nuevas casas gozaban de mejor ventilación y que se habían drenado las aguas estancadas.

Sin llegar a una remodelación urbanística drástica como la del Real Sitio, muchos pueblos emprendieron obras de saneamiento y drenaje de aguas estancadas o mejor dicho, solicitaron el permiso para hacerlo al Gobierno, porque el Gobernador del Consejo, conde de Montarco, se había encargado de recordar al Consejo de Castilla que el particular de agua y cualquier otra obra pública incumbe al Consejo, y a él corresponde dirigir todas las instancias de esta naturaleza, ya porque no pertenecen a la autoridad de la Junta Suprema [de Sanidad] y ya porque ésta sólo debe ocuparse en lo que es propio y peculiar de su instituto ${ }^{21}$.

Es decir, que los poderes locales no tenían facultad para actuar autónomamente. Una vez más se manifiesta uno de los rasgos típicos del dirigismo ilustrado: el afán por mantener el control de todas las actuaciones que ese mismo dirigismo fomentaba.

Otro motivo de preocupación para los concejos era la salubridad de los cementerios, como ocurría en Baeza ya en $1800^{22}$. De repente lo que hasta entonces había sido habitual se convertía en repugnante y nocivo, y se intentaba corregirlo movidos por la conciencia de los peligros para la salud: en este sentido, la representación del párroco de Villalazán roza lo terrorífico por lo macabro.

Precisamente por su contraste con el tradicional llamamiento a la caridad es interesante la política del Consejo para paliar los efectos de la crisis fomentando el trabajo de los jornaleros desocupados ${ }^{23}$, emprendiendo obras públicas, que en ámbito local se materializaban a menudo en mejoras higiénicas. Los 154 expedientes del Archivo Histórico Nacional abiertos a raíz de esa Real Orden ${ }^{24}$ son en su mayoría propuestas de obra pública para ocupar a jornaleros pobres. 50 de ellos se refieren a lugares golpeados por el paludismo y en 28 ocasiones no hacían sino una genérica referencia a auxiliar a los enfermos más necesitados. Parece evidente que muchos concejos de pueblos pequeños limitaban el problema de la asistencia a la disponibilidad de pan, pero es posible también leer esas propuestas como una demostración del desconcierto ante la gravedad de la crisis, la dureza de sus efectos y la falta de medios para enfrentarlos. Cuando se proponen intervenciones según las normas de la Circular, la promoción de obra pública se centra en la construcción de fuentes -10 casos- y traídas de agua potable en otros siete, lo que es indicativo del estado higiénico-sanitario de la población: si no se podía disponer de agua potable, no es de extrañar que la enfermedad fuera endémica. En una doble actuación contra la desocupación y la insalubridad de los pueblos, varios ayuntamientos proponían emprender obras de drenaje, como en Tarazona de la Mancha, en Madrigal y en Zalamea de la Serena. En fecha tan tardía como 1805 el ayuntamiento de Castrogeriz presentaba al Consejo un proyecto más ambicioso, por razones de higiene y para emplear a los braceros, que consistiría en remodelar el 
lecho del Odra, y que se financiaría con las contribuciones de los vecinos que querían "dar más madre" al río.

Los demás expedientes son de localidades que no aparecen entre las afectadas por la enfermedad, lo que significa que aprovechaban la iniciativa del Consejo para conseguir lo que no tenían, agua sana. Además de la falta de agua potable también planteaba problemas sanitarios la eliminación de los residuos del pueblo, con la necesidad de construir alcantarillas al objeto declarado de mejorar la salubridad del caserío, como en Andújar, en Badajoz, o en Bujalance, en Aranda de Duero, en Soria, en Córdoba.

Es importante notar que la financiación de las obras de utilidad pública no se dejaba como tradicionalmente ocurría al albur de la generosidad y la caridad de los particulares sino que debería cubrirse con fondos públicos y es en este sentido en que se puede hablar de un principio de asistencia pública a los necesitados. La relación de los expedientes sometidos al Consejo de Castilla indica los casos documentados y en su última columna se puede comprobar la decisión del Consejo, si autorizaba o no los trabajos propuestos. El hecho de que los gastos se cubrieran con fondos públicos, siendo un paso adelante en la visión tradicional de la intervención del Estado, no era una buena noticia para los poderes locales puesto que, al carecer prácticamente de medios, debían recurrir a la enajenación o arrendamiento de los bienes comunales. Tampoco era una buena noticia para las asociaciones laicas de carácter religioso y las obras pías, pues recurrir a sus fondos y/o bienes representaba una nueva expropiación después de la desamortización de Godoy. En cambio es significativo que de las propuestas documentadas solamente tres, el 6\%de ellas, ofrecían como fuente de financiación el recurso a la limosna, ilustrando así el rechazo a este medio como fuente fiable de ingresos. Siete lugares pretendían financiar sus proyectos recurriendo a los mismos arbitrios que se habían usado anteriormente para satisfacer necesidades del Estado, como pagar la cuota de los Trescientos Millones o el $17 \%$ de $S$. $M$, o cubrir los gastos de la construcción de alguna carretera. Nueve de los 50 expedientes hablaban de recurrir a bienes de cofradías, obras pías o del fondo pío beneficial; pero el grueso de las actuaciones se pagaría con los fondos de propios o de los pósitos $-19 \%$ de los expedientes- y la venta o arriendo de bienes comunales -38\%de los casos. El Consejo de Castilla con su medida había permitido que los ayuntamientos realizaran tareas de auxilio durante la crisis, siempre previa su autorización- pero no proporcionaba dinero para pagarlas. En el $60 \%$ de las ocasiones, por lo tanto, eran los mismos vecinos afectados quienes tenían que financiar su propio socorro, con la agravante de que para conseguirlo habían de empobrecerse ulteriormente al tener que disponer de los bienes del común.

Aunque las decisiones del Consejo son aparentemente erráticas, porque en cuatro ocasiones niegan lo que autorizan en diez -venta o arrendamiento de comunales-, rechazan en dos pueblos el recurso a los fondos de propios que permiten en otros cinco, queda resaltado quede las decisiones conocidas ninguna se opuso a la expropiación de bienes de instituciones laicas de carácter religioso -obras pías, cofradías- y las autorizara.

Pero la impotencia del gobierno queda patente cuando en mayo del año siguiente, 1804, el Consejo de Castilla reconocía que no se había emprendido ningún tipo de actuaciones para evitar los peligros denunciados. Por una parte el Gobierno había lanzado una iniciativa general que se puede considerar una tímida actuación asistencial ante la crisis, lo que tiene aspectos novedosos en relación con las intervenciones parciales y puntuales de otras coyunturas anteriores, pero por otra al hacer recaer todo el peso de la financiación en los organismos locales, y al final en los mismos afectados, mantenía la naturaleza intervencionista típica del gobierno ilustrado: proponer, dirigir, permitir o denegar actividades que otros tenían que sufragar.

\section{CONCLUSIONES: ASISTENCIA O LIMOSNA}

Para valorar el significado de la política ante la crisis es preciso tener presente que, como en muchas iniciativas propias de la llustración, la intención humanitaria primera quedaba matizada no sólo por las minuciosas disposiciones reglamentistas asociadas sino también por la preocupación de no favorecer forma alguna de holgazanería. Las medidas de asistencia social -con todo lo limitado que ese concepto puede ser en el siglo XVIII- tienen dos vertientes tan distintas como evidentes, que se manifiestan por una parte en el sentimiento caritativo y por otra en la prevención por principio contra los futuros beneficiarios, porque como el peso económico de la iniciativa se cubría con el producto de limosnas de particulares o de la Iglesia, el Consejo recelaba de los socorros indiscriminados que habrían favorecido tanto a verdaderos necesitados como a quienes llamaban malentretenidos. Las ayudas se movían en parámetros tradicionales: su gestión correspondía a "eclesiásticos virtuosos y personas seculares próvidas y caritativas", y los beneficiarios debían ser "merecedores" del socorro. A la luz de los expedientes de los pueblos se pone de manifiesto que la iniciativa corría a cargo de la buena voluntad de los pudientes; así en 
Burgo de Osma la sopa se repartía a trescientas personas con los fondos de beneficencia, diezmos, bienes de obras pías y limosnas de los vecinos. Lo que queda por determinar es si se trataba de un elemental sentimiento humanitario o por el contrario era señal de un inicio de reflexión sobre los principios de la asistencia a los desfavorecidos, teniendo presente que en no pocas ocasiones se intentaba también evitar desórdenes públicos.

La mentalidad subyacente del Consejo de Castilla queda reflejada en la declaración de propósitos de su Carta Circular17 septiembre de 1804 dirigida a los pueblos afectados por la crisis. Se debían emprender actividades de socorro con el objeto de evitar la mendicidad y la dispersión de los pobres pues "convertiría[ $n$ ] luego estas gentes en vagos o criminales". Los organismos locales debían por "prudencia y amor a la humanidad" proporcionar trabajo a los pobres jornaleros. A los impedidos por ancianidad, enfermedad u otra causa legítima se los debía socorrer "como exige la caridad" pero sin dejarlos salir de sus pueblos de origen, y siempre "observando y haciendo observar exactísimamente lo dispuesto por las leyes sobre este punto, y en razón castigar como vagamundos a los mendigos válidos o útiles para el trabajo, y averiguar los verdaderos pobres dignos de la limosna". Se recor- daba también a las Justicias locales su obligación de abstenerse "de dar pasaportes a personas que pretendan trasladar su miseria a otros pueblos cuidando además en los que den para venir a la Corte y Sitios Reales, con arreglo a lo mandado en la Real Orden de primero de julio de este año [...] y se castigará rigurosamente toda contravención".

Los poderes locales compartían el planteamiento. El pueblo de Hinojosa de la Orden contaba 200 personas entre viudas huérfanos enfermos inútiles y jornaleros "que no podían alcanzar el pan ni aun ganarlo" por lo que se recurriría a la sopa económica para que los pobres no perecieran y para que tampoco cometieran "mil desórdenes" por desesperación. En Plasencia se había empezado en 1804 la sopa económica "a que concurrían frecuentemente más de setecientos miserables" pero, una vez llegado el tiempo del trabajo en el campo,

era justo y conveniente separar del socorro a los que pudiendo trabajar y ganar la vida no lo hacían abusando de los socorros que se les dispensaba en perjuicio de los más necesitados.

Esos eran "los medios que dicta la policía bien entendida y la caridad no adulterada" 25 . 


\begin{tabular}{|c|c|c|c|}
\hline \multicolumn{4}{|c|}{ RELACIÓN DE EXPEDIENTES DE MEDIDAS DE ASISTENCIA,Y MODOS DE FINANCIACIÓN, 1803-1805. } \\
\hline LUGAR y provincia actual & PROPUESTA & FINANCIACIÓN & DECISIÓN \\
\hline Alcalá de los Gazules (Cádiz) & Reparación pozos & Arriendo de comunales & NO \\
\hline Alcalá la Real (Jaén) & Construcción de fuente pública & Suscripción pública & ¿? \\
\hline Algarinejo (Granada) & Traída de agua potable & Fondos de propios & NO \\
\hline Almendral (Badajoz) & Construcción de fuente pública & $\dot{\imath} ?$ & $\dot{\imath} ?$ \\
\hline Armallones (Guadalajara) & Auxilio a enfermos pobres & Venta de pinos quemados & $\mathrm{SI}$ \\
\hline Astudillo (Palencia) & Auxilio a enfermos pobres & Fondos de propios & $\dot{2} ?$ \\
\hline Bernuy de Coca (Segovia) & Construcción de fuente pública & Venta de comunales & $\mathrm{SI}$ \\
\hline Brozas (Cáceres) & Auxilio a enfermos pobres & Arriendo de comunales & $\dot{2} ?$ \\
\hline Burgo de Osma (Soria) & Auxilio a enfermos- sopa económica & Junta de Beneficencia & $\mathrm{SI}$ \\
\hline Cañaveral (Cáceres) & Auxilio a enfermos pobres & Venta de bienes de propios & NO \\
\hline Cañete de las Torres (Cuenca) & Auxilio a enfermos pobres & Fondos de propios & $\mathrm{SI}$ \\
\hline Caravaca (Murcia) & Traída de agua potable & Venta de bienes de propios & $\mathrm{SI}$ \\
\hline Cartagena (Murcia) & Construcción de fuente pública & Proyecto 1791 pendiente aún 1807 & $\dot{d} ?$ \\
\hline Casas de Guijarro (Cuenca) & Traída de agua potable & Arriendo de pastos comunales & $\mathrm{SI}$ \\
\hline Cedillo (Segovia) & Auxilio a enfermos pobres & Fondo pio beneficial & $\mathrm{SI}$ \\
\hline Chinchilla (Albacete) & Construcción de fuente pública & Impuesto sobre ganado y comercio & NO \\
\hline Guadalajara & Auxilio a enfermos pobres & Bienes de obras pías y limosnas & SI \\
\hline Haro (La Rioja) & Auxilio a enfermos pobres & Fondo pío beneficial & $\mathrm{SI}$ \\
\hline Langa (Cuenca) & Auxilio a enfermos pobres & Venta de comunales & $\mathrm{SI}$ \\
\hline Los Yébenes (Toledo) & Auxilio a enfermos pobres & Arriendo de comunales & $\mathrm{SI}$ \\
\hline Madrigal (Guadalajara) & Drenaje de lagunas & Fondos de obras pías & $\dot{¿} ?$ \\
\hline Mancha Real (Jaén) & Construcción de fuente pública & Venta de mostrencos y obras pías & $\mathrm{SI}$ \\
\hline Mesa de Ibor (Cáceres) & Auxilio a enfermos pobres & Venta de comunales & $\dot{¿} ?$ \\
\hline Monesterio (Badajoz) & Construcción de fuente pública & Arriendo de bienes de propios & NO \\
\hline Osma (Soria) & Auxilio a enfermos pobres & Fondos de obras pías y limosnas & $\mathrm{SI}$ \\
\hline Oviedo & Traída de agua potable & Limosnas de eclesiásticos & SI \\
\hline Paredes de Nava (Palencia) & Auxilio a enfermos pobres & Arbitrio para carretera y propios & $\dot{2} ?$ \\
\hline Piña de Campos (Valladolid) & Auxilio a enfermos pobres & Vales Reales y bienes de propios & $\mathrm{SI}$ \\
\hline Ribadeva (Oviedo) & Auxilio a enfermos pobres & Arbitrio sobre vino & $\mathrm{SI}$ \\
\hline Riopar (Albacete) & Construcción de fuente pública & Venta de pinos comunales & $\mathrm{SI}$ \\
\hline Robledo de Chavela (Madrid) & Auxilio a enfermos pobres & Venta de pinos comunales & $\mathrm{SI}$ \\
\hline S. Cebrián de Castrotorafe (Zamora) & Drenaje de aguas estancadas & Arriendo de pastos comunales & $\dot{2} ?$ \\
\hline Salamanca & Auxilio a enfermos pobres & Junta de Caridad & Ya en acto \\
\hline Salmerón (Guadalajara) & Auxilio a enfermos pobres & Sobrantes de propios & $\dot{c} ?$ \\
\hline Santander & Reparación de alcantarilla & Suscripción pública y limosnas & $\dot{\imath} ?$ \\
\hline Santa Cruz de la Zarza (Toledo) & Auxilio a enfermos pobres & Bienes de hermandades & $\mathrm{SI}$ \\
\hline Santa Olalla (Toledo) & Construcción de fuente pública & Arbitrio como para 300 millones & $\dot{2} ?$ \\
\hline Torre de Juan Abad (C. Real) & Traída de agua potable & Anticipo de pudientes con reintegro & $\mathrm{SI}$ \\
\hline Torrubia del Campo (Cuenca) & Auxilio a enfermos pobres & Fondos de propios reintegrables & $\mathrm{SI}$ \\
\hline Vadillo (Soria) & Auxilio a enfermos pobres & Venta de comunales & $\dot{i} ?$ \\
\hline Valdenebro (Soria) & Drenaje de aguas estancadas & Rentas de propios & $\dot{¿} ?$ \\
\hline Valles de Palenzuela (Burgos) & Auxilio a enfermos pobres & Arbitrio del $17 \%$ para S. $M$ & $\dot{¿} ?$ \\
\hline Vargas (Toledo) & Auxilio a enfermos pobres & Restos del Ramo de aguardientes & $\dot{2} ?$ \\
\hline Vera (Almería) & Traída de agua potable & Fondos de propios & NO \\
\hline Villahermosa (C. Real) & Auxilio a enfermos pobres & Arriendo de pastos comunales & $\mathrm{SI}$ \\
\hline Villalar (Valladolid) & Auxilio a enfermos pobres & Fondos de propios -limosna cartuja & $\dot{c} ?$ \\
\hline Villanueva del Rey(Córdoba) & Hacer dos fuentes públicas & Fondos del pósito & $\mathrm{SI}$ \\
\hline Villarrobledo (Albacete) & Auxilio a enfermos pobres & Arbitrio a consumo y comercio & NO \\
\hline Yanguas (Toledo) & Auxilio a enfermos pobres & Arriendo de pastos comunales & SI \\
\hline Zalamea La Serena (Cáceres) & Traída de agua potable & Venta de comunales & NO \\
\hline
\end{tabular}




\section{NOTAS AL FINAL}

1 A veces se señalaban también tabardillos. "Historical importance of wetlands in malaria transmission in southwest of Spain" (2009), pp. 283-300. Los primeros años del Ochocientos y los últimos del Setecientos fueron de "grandes exacerbaciones epidémicas", López Gómez, 1994 p. 634. En este mismo período hubo epidemias de fiebre amarilla en todo el arco mediterráneo de la Península.

2 Archivo Histórico Nacional (AHN), Consejos, legajos 4025/72, 2982/41, 2358/32 y 2113/21 respectivamente. En las citas se ha modernizado la grafía y la puntuación.

3 AHN, Estado legajo 3251; Real Cédula 15/V/1788 [con] instrucción inserta de lo que deberán observar los corregidores y alcaldes mayores del reino, Consejos, legajo 2487/1; Real Orden7/X/1803, Consejos, legajo 2392/44; Real Resolución22/XII/1803 Socorro de pobres enfermos de las dos Castillas, Consejos, legajo 50172; Prospecto para la formación de un establecimiento de beneficencia en la ciudad de Valladolid 11/XI/1803, Consejos, legajo 2412/22; Copia del Dictamen del Consejo proponiendo arbitrios 23/XI/1803, Consejos, legajo 50172; Real Orden 15/I/1804 Para el establecimiento de Juntas de socorro y beneficencia, Consejos, legajo 2392/3; Carta Circular 17/IX/1804,Consejos, legajo 2412/24; Expediente [...] buena policía en el punto de aseo y limpieza de los pueblos, Consejos, legajo 2487/1; Expediente [...] concediendo varios arbitrios para el socorro de los Pueblos de las dos Castillas que se hallan infestadas por la epidemia de tercianas 1804, Consejos, legajo 2423/4; Expediente [...] establecimiento de Juntas de Beneficencia 1804, Consejos, legajo 50172; Plan o arreglo de policía para el mejor aseo y limpieza de calles y plazas, Consejos, legajo 2189/18.

4 AHN, Consejos, legajos1703/16; 1948/3; 2113/21; 2154/29; 2162/21; 2165/24; 2171/14; 2338/25; 2340/19; 2346/3, 4, 8; 2351/31; 2356/31;2358/32; 2361/2; 2362/20; 2364/21; 2370/20, 28; 2376/37; 2377/5; 2378/40; 2386/35;2387/16; 2391/18; 2396/6; 2404/6, 17; 2408/11, 17; 2410/8; $2411 / 31 ; 2412 / 22,30,35 ; 2423 / 4 ; 2428 / 4,9 ; 2429 / 8,14$, 21, 25; 2462/14; 2468/44, 50; 2471/23; 2472/8; 2489/10; $2569 / 1 ; 2654 / 7 ; 2678 / 13 ; 2728 / 3 ; 2945 / 10 ; 2981 / 3$; 2982/41; 3023; 3024; 4024/37; 4025/72; 6060/116; 9685; 11948/1, 8; Estado, 3171 I y II.

5 Masdevall, José Relación de las epidemias de calenturas pútridas y malignas que en estos últimos años se han padecido en el Principado de Cataluña, Madrid, Imprenta Real, 1786 pp. 16, 113 y 61; Alsinet, José Nuevas utilidades de la quina, Madrid, Antonio Muñoz del Valle, 1774, cap. VI; Salazar, Tomás De Tratado del uso de la quina, Madrid, Viuda de Ibarra, 1791, p. 87. Abundan los tratados sobre paludismo: A.P.D.E. Medicina patria o elementos de la medicina práctica de Madrid, Madrid Antonio Muñoz, 1788; Nieto de Piña, Cristóbal Historia de la epidemia de calenturas benignas que se experimentó en Sevilla [...] 1784, Sevilla, Imprenta Mayor, s.a.; Pacheco Ortiz, Félix Rayos de luz práctica [...] debida curación de las fiebres intermitentes, Madrid, Isabel Nicasia Barberán, 1731; Piquer, Andrés Tratado de calenturas, Madrid, Blas Román, 1788; Pons, Francisco Memoria práctica sobre las calenturas pútridas del Ampurdán, Barcelona, Eulalia Piferrer, 1790; Sánchez, Juan Relación de la epidemia... Madrid, Blas Román, 1789; Sastre y Puig, Juan Reflexiones instructivo-apologéticas sobre el eficaz y seguro método de curar las calenturas pútridas y malignas inventado por el IIle. Dr. Dn. Joseph de Masdevall, Cervera, Imprenta de la Universidad, 1788; Suárez de Ribera, Francisco Medicina invencible legal, o teatro de fiebres intermitentes complicadas, Madrid, Francisco del Hierro, 1726. Masdevall (1786) p. 61.

6 AHN Consejos, legajo 50172.Capel Sáez, 1998-1999, pp. 79 105.

7 Rumford, Benjamin Essais politiques, économiques et philosophiques, I, Essai III, Génève, Manget, 1799 pp. 201-208. Sobre Rumford, Clément, 2010

8 Demerson, 1969; Peset-De Carvalho, 1972.

9 AHN Consejos, legajos 2489/10; 2346/8; 2471/23; 2468/50; 2945/10.

10 Achote o achiote (Bixa Orellana), planta originaria de Centroamérica usada como colorante y condimento. Su presencia en la gastronomía andaluza en el siglo XVIII es un ejemplo notable de las relaciones culturales entre los dos continentes, ratificada por la mención siguiente a otra especia americana, la pimienta de Tabasco.

11 Proyecto económico y caritativo para socorrer a los pobres de esta ciudad de Córdoba. Córdoba, Imprenta Real de D. Rafael García Rodríguez y Cuenca, 1805, pp. 17-19, 20, $23-$ 24.

12 "Sin este vegetal hubieran sido víctimas del mal innumerables que hoy viven sanos y robustos". Salazar, Tomás De Tratado del uso de la quina, Madrid, Viuda de Ibarra, 1791 p. XVI.

13 AHN Consejos, legajo 2341/14

14 AHN Consejos, legajo 2165/24

15 AHN Consejos, legajo 2410/8.

16 Jori, 2013a. Castellanos, 1990, habla del "metabolismo urbano" en Málaga e indica la inexistencia de sistemas de eliminación de la excreta y lo rudimentario del abastecimiento de agua potable. Mismas consideraciones en Carrillo Martos, 1990.

17 AHN Consejos, legajo 2340/19.

18 AHN Consejos, legajos 2412/22; 2162/21; 2171/14.

19 Medina Sidonia 21/III/1803. AHN Consejos, legajo 2171/14.

20 Alsinet, José Nuevas utilidades de la quina, Madrid, Antonio Muñoz del Valle, 1774 Prevención, párr. 4.

21 22/VIII/1804. AHN Estado, legajo 2928-I/55

22 AHN Consejos, legajos1963/1 Baeza; 4024/96 Villalazán.

23 La política de fomento de obra pública es objeto de una investigación en curso. Aquí sólo se reseñan los casos referidos a obras para mejorar las condiciones higiénico-sanitarias de los pueblos afectados por las epidemias.

24 CC 7/X/1803, AHN Consejos, legajo 2392/44. Véase nota 4.

25 AHN Consejos, legajos 2370/28 Hinojosa de la Orden, 2391/18 Plasencia. 


\section{BIBLIOGRAFÍA}

Alberola Romá, Armando (1985), “Una enfermedad de carácter endémico en el Alicante del XVIII: las fiebres tercianas", Revista de Historia Moderna, 5, pp. 127-140.

Alberola Romá - Bernabé Gil (1998-1999), “Tercianas y calenturas en tierras meridionales valencianas: una aproximación a la realidad médica y social del siglo XVIII", Revista de Historia Moderna, 17, pp. 95-112.

Astorgano Abajo; Garrido Domené (2017), “El paludismo en Palencia (1800-1804) a través del Canto Votivo del jesuita Tolrá", Asclepio, 69 (1).

Bernal, Miguel (1978), "Haciendas locales y tierras de propios. Funcionalidad económica de los patrimonios municipales", Hacienda pública española, 55, pp. 285-312.

Bonastra, Quim (2000), "Innovaciones y continuismo en las concepciones sobre contagios y las cuarentenas en la España del siglo XIX. Reflexiones acerca de un problema sanitario, económico y social", Scripta Nova, 69, (35). Disponible en www.ub.edu/geocrit/sn-69-35.htmconsultado 12 diciembre 2017.

Bueno Marí; Jiménez Peydró, (2010), “Crónicas de arroz, mosquitos y paludismo en España: el caso de la provincia Valencia (S. XVIII-XX), Hispania, 236 pp. 687-708.

Buj Buj, Antonio (2000), "De los miasmas a la malaria", Scripta Nova, 69 (42).

Campos, R.; Perdiguero-Gil, E.; Bueno, E. (eds.) (2020),Cuarenta historias para una cuarentena: reflexiones históricas y salud global. Madrid: SEHM. https://sehm.es/wp-content/ uploads/2020/08/Cuarenta-historias-para-una-Cuarentena. pdf

Capel Sáez, Horacio (1998-1999), “Medicina y clima en la España del siglo XVIII", Revista de Geografía, 32-33, pp. 79-105.

Carrillo Martos, Juan Luis (1990), “Enfermedad y Sociedad en la Málaga de la Ilustración: del tifus exantemático a la fiebre amarilla", Ciencia, Técnica y Estado en la España ilustrada, Zaragoza, Sociedad Española de Historia de las Ciencias y las Técnicas, pp. 413-423

Castejón Porcel, Gregorio (2015), “El paludismo en Fuente Álamo de Murcia en los siglos XVIII y XIX", Investigaciones Geográficas, 64, pp. 87-103.

Castellanos, Jesús (1990), "La infraestructura de saneamiento en la Málaga de la llustración: cambio y repercusiones", Ciencia, Técnica y Estado en la España ilustrada, Zaragoza, Sociedad Española de Historia de las Ciencias y las Técnicas, pp. 425-445.

Clément, Jean-Pierre (2010), “La sopa económica de Rumford, o la beneficencia empresarial en el siglo XVIII", Disponible en http://www.cervantesvirtual.com/obra/la-sopa-economicarumford-o-la-beneficencia-empresarial-en-el-sigloxviii-775323/. Consultado 22 septiembre 2017.

Demerson, Paula (1969), "La distribución de sopas económicas por la Real Sociedad Matritense en 1803-1804", Boletín de la Real Academia de la Historia, CLXIV, I, pp. 119-135.
Díaz Pintado, Juan (1992), Epidemias de paludismo en la Mancha del XVIII. Disponible en www.estudiosmanchegos.castillalamancha.es. Consultado 28 agosto 2017.

Feria Lorenzo; Ramos Cobano (2013), "Salus populi suprema lex esto: fe, ciencia y política en la modernización de las prácticas funerarias (siglos XVIII-XIX)", Historia, 396, 2, pp. 217248.

Gänger, Stefanie Masdevall's 'Antipyretic Opiate', or: A Well-Travelled Recipe. Disponible en https://recipes.hypotheses. org/8078 consultado 6 septiembre 2017.

García Colmenares, Pablo (1987), "Sociedad, sanidad y muerte..." Actas I Congreso de Historia de Palencia, III, pp. 679-714.

Giménez-Font, Pablo (2008), “La epidemia de malaria de 17831786: nota sobre la influencia de anomalías climáticas y cambios de uso del suelo en la salud humana", Investigaciones Geográficas, 46, pp. 141-157.

Grima, Francisco (1989), La introducción de la salud pública en la medicina española del siglo XVIII, Un. Murcia.

"Historical importance of wetlands in malaria transmission in southwest of Spain", Limnetica, 28, 2, 2009, pp. 283-300.

Jori, Gerard (2013a), "La ciudad como objeto de intervención médica. El desarrollo de la medicina urbana en España durante el siglo XVIII", Scripta Nova, XVII, 431.

Jori, Gerard (2013b), "Población, política sanitaria e higiene pública en la España del siglo XVIII", Revista de Geografía, 54, pp. 129-153.

López Gómez, José Manuel (1988), “Paludismo y sociedad en Mérida (1700-1833)" Proserpina, 7, pp. 51-64.

López Gómez, José Manuel (1994), “La epidemia palúdica de 1804 en las provincias de Burgos y Palencia", Actas I XXXIII Congreso Internacional de Historia de la Medicina, Sevilla, pp. 633-650.

Maza, E. (1987). Pobreza y asistencia social en España, siglos XVI al XX: aproximación histórica. Valladolid: Universidad de Valladolid.

Pascual Arriaga, Mercedes (2002), "La ciudad ante el contagio: medidas políticas y administrativas dictadas en la epidemia de fiebre amarilla de 1804 en Alicante" Asclepio, LIV, pp. 125-153.

Peset; Carvalho, (1972), "Hambre y enfermedad en Salamanca. Estudios de la repercusión de la "crisis de subsistencia» de1803-1805 en Salamanca" Asclepio, XXIV, pp. 225-266.

Peset Reig, José Luis y Mariano (1972a), Muerte en España (política y sociedad entre la peste y el cólera), Madrid, Seminarios y Ediciones.

Peset Reig, José Luis y Mariano(1972b), "Cultivos de arroz y paludismo en la Valencia del siglo XVIII" Hispania, 121, págs. 277-375.

Peset Reig, José Luis y Mariano (1978). Epidemias y sociedad en la España del Antiguo Régimen. Estudios de Historia Social, 4, 7-28. Disponible en: http://roderic.uv.es/ handle/10550/73082. Reher, Sven-David (1980), “La crisis de 1804 y sus repercusiones demográficas: Cuenca (17751825)" Moneda y Crédito 154, pp. 35-73. 
Riera; Granda; Llansol, (1988), Epidemias y paludismo en la ribera del Júcar, Un. Valladolid.

Riera Palmero, Juan José (1980), Masdevall y la medicina española ilustrada, Un. Valladolid.

Riera Palmero, Juan (1982), Estudios y documentos sobre arroz y paludismo en Valencia (siglo XVIII), Un. Valladolid.

Riera Palmero, Juan (1984),Fiebres y paludismo en la España ilustrada. Félix Ibáñez y la epidemia de La Alcarria, 17841792, Un. Valladolid.

Riera Palmero, Juan (1987), "Epidemiología y tercianas en Tierra de Campos" Actas / Congreso de Historia de Palencia, 3 pp. 671-678.

Riera Palmero, Juan (1994), “Quina y malaria en la España del siglo XVIII" Medicina \& Historia, 52, pp. 1-16.
Rodríguez Ocaña, Esteban (1990), “Organización sanitaria española en el siglo XVIII: las Juntas de Sanidad", Ciencia, técnica y estado en la España ilustrada, Zaragoza, Sociedad Española de Historia de las Ciencias y las Técnicas, pp. 399-411.

Rodríguez Ocaña, Esteban (2005), Salud pública en España, Un. Granada.

Sáez Gómez - Marset Campos (1990), “La consolidación de la sanidad municipal en la España del siglo XVIII: la salud pública en Murcia", Medicina \& Historia, 31 pp. 1-16.

Sobrevía Clavera, Andrés (2004), "El cultivo del arroz de secano en Cataluña (1778-1839). Una propuesta agronómica al problema del paludismo" Asclepio, LVI-2, pp. 169-196. 